\title{
Ensemble projection of the sea level rise impact on storm surge and inundation at the coast of Bangladesh
}

\author{
Mansur Ali Jisan, Shaowu Bao, and Leonard J. Pietrafesa \\ Department of Coastal and Marine Systems Science, Coastal Carolina University, Conway, South Carolina, USA
}

Correspondence: Mansur Ali Jisan (mjisan@g.coastal.edu)

Received: 16 June 2017 - Discussion started: 17 July 2017

Revised: 4 December 2017 - Accepted: 10 December 2017 - Published: 24 January 2018

\begin{abstract}
The hydrodynamic model Delft3D is used to study the impact of sea level rise (SLR) on storm surge and inundation in the coastal region of Bangladesh. To study the present-day inundation scenario, the tracks of two known tropical cyclones (TC) were used: Aila (Category 1; 2009) and Sidr (Category 5; 2007). Model results were validated with the available observations. Future inundation scenarios were generated by using the strength of TC Sidr, TC Aila and an ensemble of historical TC tracks but incorporating the effect of SLR.
\end{abstract}

Since future change in storm surge inundation under SLR impact is a probabilistic incident, a probable range of future change in the inundated area was calculated by taking into consideration the uncertainties associated with TC tracks, intensities and landfall timing.

The model outputs showed that the inundated area for TC Sidr, which was calculated as $1860 \mathrm{~km}^{2}$, would become $31 \%$ larger than the present-day scenario if a SLR of $0.26 \mathrm{~m}$ occurred during the mid-21st-century climate scenario. Similarly to that, an increasing trend was found for the end-21stcentury climate scenario. It was found that with a SLR of $0.54 \mathrm{~m}$, the inundated area would become $53 \%$ larger than the present-day case.

Along with the inundation area, the impact of SLR was examined for changes in future storm surge level. A significant increase of $14 \%$ was found in storm surge level for the case of TC Sidr at Barisal station if a SLR of $0.26 \mathrm{~m}$ occurred in the mid-21st century. Similarly to that, an increase of $29 \%$ was found at storm surge level with a SLR of $0.54 \mathrm{~m}$ in this location for the end-21st-century climate scenario.

Ensemble projections based on uncertainties of future TC events also showed that, for a change of $0.54 \mathrm{~m}$ in SLR, the inundated area would range between 3500 and $3750 \mathrm{~km}^{2}$, whereas for present-day SLR simulations it was found within the range of $1000-1250 \mathrm{~km}^{2}$

These results revealed that even if the future TCs remain at the same strength as at present, the projected changes in SLR will generate more severe threats in terms of surge height and the extent of the inundated area.

\section{Introduction}

In addition to routine inundation from upstream river water and the downstream tides, the coastal part of Bangladesh is frequently flooded by storm surges induced by tropical cyclones (TCs). Typically, TC-induced storm surges in this area initiate in the central or southern part of the Bay of Bengal or near the Andaman Sea. TCs normally occur during April-May, the pre-monsoon period, and again from October to November, the post-monsoon period. Harris (1963) mentioned that five basic processes (i.e. pressure, direct wind, earth's rotation, waves and rainfall effects) cause the water level rise under storm conditions. Pietrafesa et al. (1986) also pointed out that high water at the mouths of coastal estuaries, bays, and rivers can block discharges of upstream waters and contribute to upstream flooding, a non-local effect. Among these processes, storm surges form primarily due to the TC wind stresses mechanically driving the surface frictional layer onshore. Assuming an idealized balance between pressure gradient force and surface wind stress with assumed small bottom stress, the surge related to TC wind stress can be expressed as $\Delta \eta=\frac{\tau_{\mathrm{W}} L}{g \rho h}$, where $L$ is the fetch of the wind (the distance over which the wind blows), $\tau_{\mathrm{w}}$ is the wind stress due to the friction between the moving air and water surface, $g$ is the gravity, $\rho$ is the density of water, $h$ is the 
depth near the coast (Hearn, 2008). Also, as a secondary process, due to the differences in pressure level, the water level rises in the areas of low atmospheric pressure and falls in the areas of high atmospheric pressure, which is how the rising water level offsets the low atmospheric pressure to keep the total pressure constant (Harris, 1963).

According to Murty et al. (1986), the surge amplifies as it approaches the coast due to the shallow continental shelf of the Bay of Bengal and hence it causes massive flooding in the low-lying coastal areas. A large percentage of the Bangladeshi population resides in the low-lying coastal regions of the country. Most of the areas near the coastal zone of Bangladesh have been formed by the process of riverine sedimentation and because of that the low-lying areas are relatively flat and as such are susceptible to flooding even under normal astronomical tide conditions. Furthermore, the triangular shape of the Bay of Bengal region makes storm surges more distressing, as a funnelling effect occurs. The geomorphological characteristics of the region have made the locales prone to major TC events, events which have occurred multiple times in the past, directly causing loss to lives, property, livelihoods and the economy of the country (Haque, 1997).

Future climate change scenarios may further exacerbate the threats of TC-induced storm surge and inundation. According to the Intergovernmental Panel on Climate Change Fourth Assessment Report (IPCC 4AR), there is a high probability of major changes in TC activity across various ocean basins including the Arabian Sea and the Bay of Bengal. According to Milliman et al. (1989), this Ganges-BrahmaputraMeghna delta region has long been characterized as a highly vulnerable zone due to its exposure to the increasing trend of SLR. According to the SLR analysis done by the South Asian Association for Regional Cooperation based on the 22year records at Charchanga, Cox's Bazar and Hiron Point, sea level at these locations is rising at rates of 6.0, 7.8 and $4 \mathrm{~mm} \mathrm{yr}^{-1}$ (SMRC, 2003). These rates are much higher than the global rate of SLR $\left(\sim 3.2 \mathrm{~mm} \mathrm{yr}^{-1}\right)$ over the last 25 years (Pietrafesa et al., 2015). Based on Warrick et al. (1996), the sea level in the Bay of Bengal is also influenced by local factors, including tectonic setting, deltaic processes, and sediment load; for example, the coastal region of Bangladesh has been subsiding due to the pressure on the Earth's crust from the sediment with thick layers that have formed over millions of years. Warrick et al. (1996) also analysed the recent history of land accretion and suggested that the subsidence is also balanced by land accretion due to sediment supply from the coast. These physical phenomena have been shaping the coast of Bangladesh over the past 100 years. A global SLR of $26-59 \mathrm{~cm}$ has been projected over the next 84 years to 2100 by the IPCC under the scenario A1F1 (Meehl et al., 2007). In this proposed work, we will use the SLR projections from Caesar et al. (2017), which is based on IPCC AR5 and suggests projections of SLR of $26 \mathrm{~cm}$ for the middle of the $21 \mathrm{st}$ century (2040-2060) and $54 \mathrm{~cm}$ for the end of the $21 \mathrm{st}$ century (2079-2099).
Previous studies have analysed the likely impact of climate change, especially SLR, on storm surge and inundation in this region. Using hydrodynamic models, Ali (1996) showed that with increases of 1.0 and $1.5 \mathrm{~m}$ of SLR (10 and $15.5 \%$ ), the entirety of Bangladesh would get flooded under the strength of future TCs. Karim and Mimura (2008) used a 1-D hydrodynamic model to study inundation under several scenarios of climate and for the case of future TCs by changing sea surface temperature, SLR, wind speed and sea level pressure. Based on their results, Karim and Mimura (2008) concluded that with an increase of $2{ }^{\circ} \mathrm{C}$ in SST and $0.3 \mathrm{~m}$ of SLR, the flood risk area would be $15.3 \%$ more than the present-day risk area and the depth of flooding would increase by as much as $22.7 \%$ within $20 \mathrm{~km}$ from the coastline. Both Ali (1996) and Karim and Mimura (2008) considered SST rise and the future strength of TCs when simulating the future storm surge and inundation.

However, the impacts of climate change on the frequency and intensity of TCs are still debatable (Knutson et al., 2010). The projection of the TC characteristics in the Bay of Bengal region is unclear as well. To improve these uncertainties, a reasonable method with which to examine the impact of future SLR on storm surge and inundation would be to construct an ensemble of tracks and intensities of possible landfalling TCs along the Bangladesh coast based on the historical TC records. From this statistical approach, we can quantify the probable impact of TC tracks under future SLR change. To date, such an approach has not been done and will be the method of this study.

We first use Delft3D to simulate the present-day storm surge and inundation using the strength of two recent TCs (Sidr and Aila) and validate the simulations with observational data. The future storm surge and inundation scenarios were then generated by incorporating the projected SLR.

The study was carried out in the Ganges-BrahmaputraMeghna delta region (Fig. 1a). According to the Integrated Coastal Zone Management plan, 19 districts of Bangladesh located near the Bay of Bengal area were defined as the coastal areas and considered in this study. We selected two TC cases in this study: a strong Saffir-Simpson (SS) Category 5 that directly hit the study area, TC Sidr, and a Category 1 storm that made landfall in the south-western part of the study domain, TC Aila.

TC Sidr made landfall near the Barguna district (Fig. 1a) in 2007, causing $\sim 3000$ human fatalities and leaving millions homeless. This Category 5 cyclone is considered one of the most powerful cyclones in the past 15 years to have made landfall in Bangladesh and affected over nine million people living in the coastal areas. The districts of Patuakhali, Khulna, Barguna and Jhalokathi were badly affected. During TC Sidr, around $15 \%$ of the affected population took refuge in nearby cyclone shelters. In the village of Angul Kata in Barguna district, around 1500 people took shelter in eight reinforced pillars to protect themselves from the tidal surge of 
(a) Study area

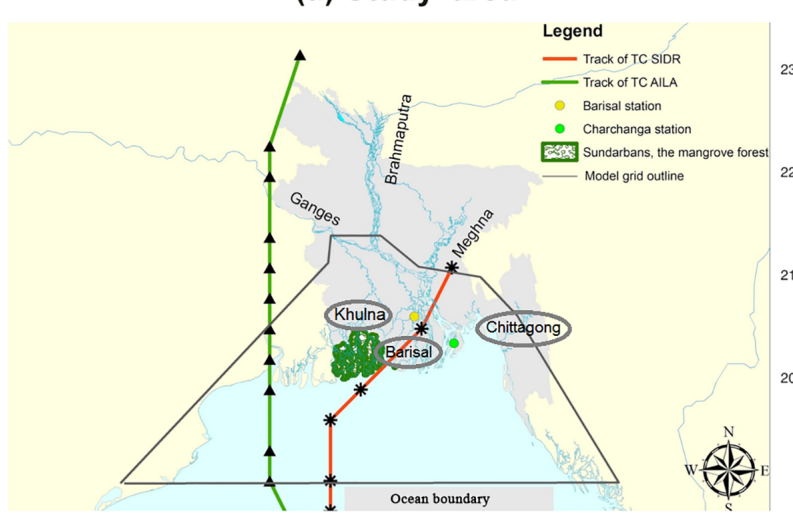

(b) Topography and bathymetry

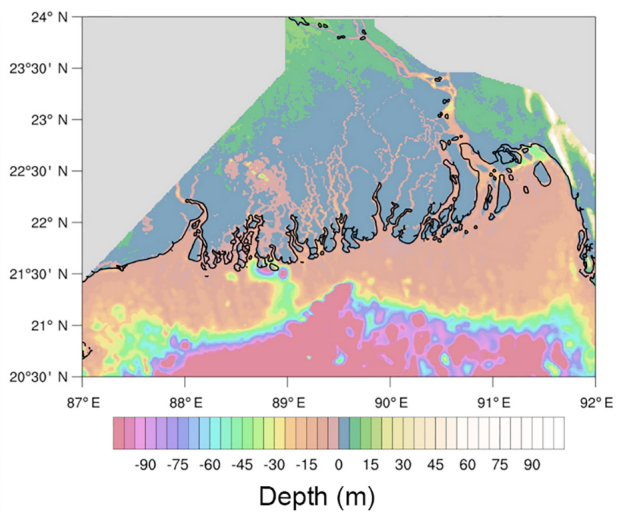

Figure 1. (a) Map of the study area for this work. The red and green lines represent the tracks of TC Sidr and TC Aila respectively. The area marked in green indicates the Sundarban mangrove forest region. Locations of the Ganges, Brahmaputra and Meghna rivers are shown on the map. Khulna, Barisal and Chittagong, which are landfall locations for the historical TCs used for ensemble projection, are shown inside a circular box on the map. Two circles over the study area are the observation stations of Bangladesh Inland Water Transport Authority (BIWTA). The black-coloured outline shows the extent of the model grid over the region. (b) Topography and bathymetry of the model domain. Negative depth values represent water bodies (ocean and rivers) and positive depth values areas represent land.

around $5 \mathrm{~m}$. If there had been no shelters, the death toll could have reached into the hundreds in that area.

The other cyclone studied in this paper, TC Aila (Fig. 1a) occurred in the Bay of Bengal region in 2009. Although a Category 1 storm, Aila, caused $\sim 190$ deaths and affected 4.8 million people, the devastation left a long-term impact. The locales mainly affected were Khulna, Patuakhali and Chandpur. The storm surge due to Aila broke a dam in Patuakhali and submerged five villages, destroying a huge number of homes and leaving thousands of people homeless. Most of the people living in those affected areas took shelter in the nearest cyclone shelters. According to government sources, approximately 2500000 houses had been destroyed completely and 3700000 houses had been damaged.

The structure of the paper is as follows: a brief description of the Delft3D-FLOW model and the methodologies used to simulate future changes in storm surge and inundation to generate ensemble projections of storm surge inundation are discussed in Sect. 2. In Sect. 3, validation of the model results, present-day storm surge inundation scenarios, ensemble projection of storm surge inundation and future change in storm surge level ${ }^{1}$ are presented. Section 4 includes discussion of model results and the uncertainties associated with the future projections. Finally, Sect. 5 presents the concluding remarks on research findings.

\footnotetext{
${ }^{1}$ In this paper, the storm surge results refer to the total water level including both normal tides and the water level change due to storm.
}

\section{Methodology}

\subsection{Modelling methodology}

\subsubsection{Application of the numerical model}

To develop the present-day and future inundation scenario in the coastal regions of Bangladesh, the Delft3D-FLOW (Delft Hydraulics, 2006), a multidimensional (2-D or 3D) hydrodynamic and transport simulation programme was used that calculates non-steady flow and transport phenomena resulting from tidal and meteorological forcing. Delft3DFLOW solves the unsteady shallow water equation in two (depth-averaged) or three dimensions. The system of equations consists of the horizontal equations of motion, the continuity equation and the transport equations for conservative constituents. The equations are formulated in orthogonal curvilinear coordinates or in spherical coordinates. Delft3D-FLOW module's two-dimensional, depth-averaged flow equations can be applied to model tidal waves, storm surges, tsunamis, harbour oscillations (seiches) and transport of pollutants in vertically well-mixed flow regimes. In this paper Delft3D's 2-D mode for barotropic depth-integrated flow has been applied. The equations are listed below.

$$
\begin{aligned}
\frac{\partial \zeta}{\partial t} & +\frac{1}{\sqrt{G_{\xi \xi}} \sqrt{G_{\eta \eta}}} \frac{\partial\left[(d+\zeta) v \sqrt{G_{\eta \eta}}\right]}{\partial \xi} \\
& +\frac{1}{\sqrt{G_{\xi \xi}} \sqrt{G_{\eta \eta}}} \frac{\partial\left[(d+\zeta) v \sqrt{G_{\xi \xi}}\right]}{\partial \xi}=Q
\end{aligned}
$$




$$
\begin{aligned}
\frac{\partial u}{\partial t}+ & \frac{u}{\sqrt{G_{\xi \xi}}} \frac{\partial u}{\partial \xi}+\frac{v}{\sqrt{G_{\eta \eta}}} \frac{\partial u}{\partial \eta}+\frac{u v}{\sqrt{G_{\xi \xi}} \sqrt{G_{\eta \eta}}} \frac{\partial \sqrt{G_{\xi \xi}}}{\partial \eta} \\
& -\frac{v^{2}}{\sqrt{G_{\xi \xi} \sqrt{G_{\eta \eta}}}} \frac{\partial \sqrt{G_{\eta \eta}}}{\partial \xi}-f v+\frac{g}{\sqrt{G_{\xi \xi}}} \frac{\partial \zeta}{\partial \xi} \\
& =-\frac{1}{\rho_{0} \sqrt{G_{\xi \xi}}} \frac{\partial P_{\mathrm{atm}}}{\partial \xi}+F_{\xi} \\
\frac{\partial v}{\partial t}+ & \frac{u}{\sqrt{G_{\xi \xi}} \frac{\partial v}{\partial \xi}}+\frac{v}{\sqrt{G_{\eta \eta}}} \frac{\partial v}{\partial \eta}+\frac{u v}{\sqrt{G_{\xi \xi}} \sqrt{G_{\eta \eta}}} \frac{\partial \sqrt{G_{\xi \xi}}}{\partial \eta} \\
& -\frac{u^{2}}{\sqrt{G_{\xi \xi} \sqrt{G_{\eta \eta}}}} \frac{\partial \sqrt{G_{\xi \xi}}}{\partial \eta}+f u+\frac{g}{\sqrt{G_{\xi \xi}}} \frac{\partial \zeta}{\partial \xi} \\
= & -\frac{1}{\rho_{0} \sqrt{G_{\eta \eta}}} \frac{\partial P_{\mathrm{atm}}}{\partial \eta}+F_{\eta}
\end{aligned}
$$

where $\xi, \eta$ are the spatial coordinates, $\zeta$ represents the water level above some horizontal plane of reference $(\mathrm{m}), u$ and $v$ are the velocities in the $\xi$ and $\eta$ direction $\left(\mathrm{m} \mathrm{s}^{-1}\right), d$ is the water depth below some horizontal plane of reference $(\mathrm{m})$, $f$ is the Coriolis forcing due to the rotation of the earth, $g$ is the acceleration of gravity $\left(\mathrm{m} \mathrm{s}^{-2}\right), P_{\text {atm }}$ is the atmospheric pressure at the water surface $\left(\mathrm{kg} \mathrm{m}^{-1} \mathrm{~s}^{-2}\right), Q$ is the discharge of water, evaporation or precipitation per unit area $\left(\mathrm{m} \mathrm{s}^{-1}\right), \rho_{0}$ is the density of water, $\sqrt{G_{\xi \xi}}$ is the coefficient used to transfer one coordinate system into another one $(\mathrm{m})$, $F_{\xi}$ is the turbulent momentum flux in $\xi$ direction $\left(\mathrm{m} \mathrm{s}^{-2}\right)$, $F_{\eta}$ is the turbulent momentum flux in $\eta$ direction $\left(\mathrm{m} \mathrm{s}^{-2}\right)$. Along with the appropriate set of initial and boundary conditions, the above-mentioned equations have been solved on an Arakawa-C type finite difference grid. Delft3D-FLOW manual (Delft Hydraulics, 2006) contains detailed information about these numerical aspects.

\subsubsection{Model grid and bathymetry}

The grid was set up using spherical coordinates. The grid spacing varies from a minimum of $125 \mathrm{~m}$ to a maximum of $1140 \mathrm{~m}$. The finer resolution was applied over land to calculate the inundation or wetting process accurately.

In this study, the land topography data were obtained from NASA's Shuttle Radar Topography Mission (SRTM) $90 \mathrm{~m}$ resolution data sets (Fig. 1b). The bathymetries of the rivers and estuaries are specified using the cross sections measured by the Institute of Water and Flood Management, Bangladesh. The ocean bathymetry was specified using the data from the General Bathymetric Chart of the Oceans 30 arcsec interval gridded data (BODC, 2003, Fig. 1b). Bathymetry and topographic data were interpolated over the model domain using triangular interpolation and grid-cell averaging methods of Delft3D (Delft Hydraulics, 2006).

\subsubsection{Wind and pressure field}

Track data of TCs Sidr and Aila were obtained from the Indian Meteorological Department (http://www.imd.gov.in). Using those data as input, TC surface winds and mean sea level pressure fields were generated using the Wind Enhancement Scheme (WES) (Heming et al., 1995) method based on the analytical equation by Holland (1980). Delft3D slightly improved the original WES by introducing TC asymmetry. Unlike some previous method that incorporates TC wind asymmetry information from observations (Xie et al., 2006), in WES the asymmetry was brought about by applying the translation speed of the cyclone centre displacement as the steering current and by introducing rotation of wind speed due to friction (Delft Hydraulics, 2011; Heming et al., 1995).

According to Holland's equation, gradient wind speed $V_{\mathrm{g}}(r)$ at a distance $r$ from the Centre of the cyclone is expressed as the following:

$V_{\mathrm{g}}(r)=\left[\frac{A B\left(p_{\mathrm{n}}-p_{\mathrm{c}}\right) \exp \left(-\frac{A}{r^{B}}\right)}{\rho r^{B}}+\frac{r^{2} f^{2}}{4}\right]^{0.5}-\frac{r f}{2}$.

Here $\rho$ is the density of air, $p_{\mathrm{c}}$ is the central pressure and $p_{\mathrm{n}}$ is the ambient pressure and the Coriolis parameter is represented by $f$. $A$ and $B$ are determined empirically, with the physical meaning of $A$ as the relation of pressure or wind profile relative to the origin and parameter $B$ defining the shape of the profile. Delft3D introduces a central pressure drop of $p_{\mathrm{d}}=p_{\mathrm{n}}-p_{\mathrm{c}}$. By equating $\frac{\mathrm{d} V_{\mathrm{g}}}{\mathrm{d} r}=0$ and assuming $f=0$ in the region of maximum winds where the Coriolis force is small compared to the pressure gradient and centrifugal forces, the radius of maximum winds $R_{\mathrm{w}}$ can be given as follows:

$R_{\mathrm{W}}=A^{1 / B}$.

Thus, $R_{\mathrm{w}}$ is independent of the relative values of ambient and central pressure and is defined entirely by the scaling parameters $A$ and $B$. Substitutions lead to the expression for the maximum wind speed $V_{\mathrm{m}}$

$V_{\mathrm{m}}=\left[\frac{B p_{\mathrm{d}}}{\rho e}\right]^{0.5}$,

where $e$ is the base of the natural logarithm $(=2.71828182846)$.

Complete details on this method can be found in the user manual of Delft3D-FLOW (Delft Hydraulics, 2006), Holland (1980) and Vatvani et al. (2002).

The circular grid of TC wind fields used in this study consists of 36 columns and 500 rows and the data were updated at 6 hourly intervals throughout its movement until landfall. Figure 2 shows a snapshot of the wind field of TC Sidr over the model domain before landfall, generated using Holland's equation above. 


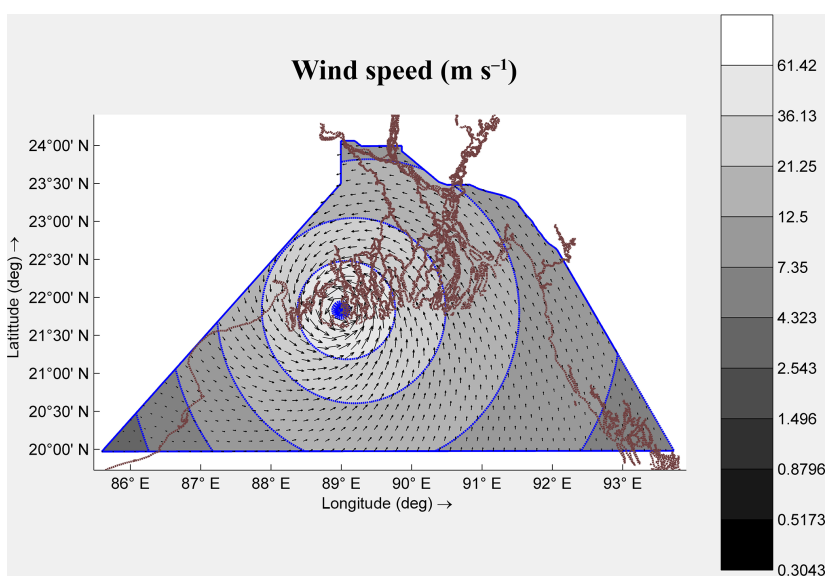

Figure 2. Distribution of the wind field over the model domain for TC Sidr during landfall generated using Holland's equation.

\subsubsection{Roughness}

The spatially varying Manning's roughness value was defined based on land cover, such as vegetation, rivers and ocean (Table 1). In the study domain, a mangrove forest, Sundarbans, is located in the south-western region, near TC Sidr's landfall location (Fig. 1a). Sakib et al. (2015) found that Sundarban plays a significant role as a buffer in reducing the total inundation during TC passages. Therefore, in this study, the mangrove region was considered. In selecting the roughness values, methods described in Zhang et al. (2012) were followed and slightly modified values were defined for the study area based on the vegetation types in that area.

\subsubsection{Boundary conditions}

Upstream boundaries were specified as discharges at the mouths of the three major rivers, the Ganges, the Brahmaputra and the upper Meghna, obtained from the Bangladesh Water Development Board (BWDB) as daily discharge. The downstream ocean boundary was defined by the Topex/Poseidon Inverse Tidal model, based on Egbert et al. (1994). Location of the downstream ocean boundary is shown in Fig. 1a.

\subsection{Calculation procedure for present-day and future storm surge and inundation scenario}

To generate storm surge and inundation for the present-day climate scenario, upstream discharge and downstream water level data from the present day were used. For future SLR scenarios, present-day hydrodynamic conditions and the strengths of present-day TCs were used but the future sea level was modified based on the SLR projections by Caesar et al. (2017). Scenarios were generated for both the mid-21st-century and the end-21st-century time horizons for these TCs, Sidr and Aila. Finally, comparisons were made in
Table 1. Manning's roughness coefficient for different land covers.

\begin{tabular}{lr}
\hline Land cover & $\begin{array}{r}\text { Manning's } \\
\text { coefficient }\end{array}$ \\
\hline River & 0.015 \\
Mangrove & 0.080 \\
Ocean & 0.01 \\
Land & 0.025 \\
\hline
\end{tabular}

terms of storm surge and inundation to identify the changes between present-day and future SLR scenarios.

Now, future storm surge inundation due to SLR is a probabilistic event that requires the uncertainties associated with the input parameters to be properly addressed. To do this and obtain statistically significant results, we created an ensemble of tropical cyclone tracks. The ensemble tracks were generated from different historical tropical cyclones that made landfall over the study domain with different intensities (Table 2). Along with the uncertainties associated with future landfall locations, the intensities of Sidr-like and Aila-like TCs may be different. So, to address the uncertainty with the intensity, we increased and decreased their intensity by $10 \%$ to simulate a probable range of future storm surge inundation.

Storm surge inundation can also vary based on landfall timing. If a storm made landfall during the high astronomical tide condition, its flooding would have been much higher at that time than what could happen during a low astronomical tide condition. For example, the tides shown in Figs. 3 and 7 as the water level oscillations have amplitudes as high as $3 \mathrm{~m}$, which could significantly affect the extension of flooded area, depending on whether the storm's landfall coincides with a high tide or a low tide. We note that TC Sidr and TC Aila made landfall during the high-tide conditions, which may not always be applicable for the future TCs. To also address uncertainties with the TC landfall timing, experiments were conducted by changing the timing of the landfall to identify the impact of high tide and low tide on storm surge and inundation. The change of timing in these tide-related experiments was implemented by modifying the tracks of the storms so that their landfalls coincide with a high tide, a tide, or a zero-tide condition, in addition to their actual tidal phases. Here in this study, future storm surge inundation scenarios caused by the ensemble tracks will then be simulated by incorporating the projected SLR. By taking all these parameters into consideration, we conducted a total of 108 ensemble simulations (36 for each of one present-day and two SLR scenarios). Parameters that were considered in making ensemble projections are shown in Table 3 . 

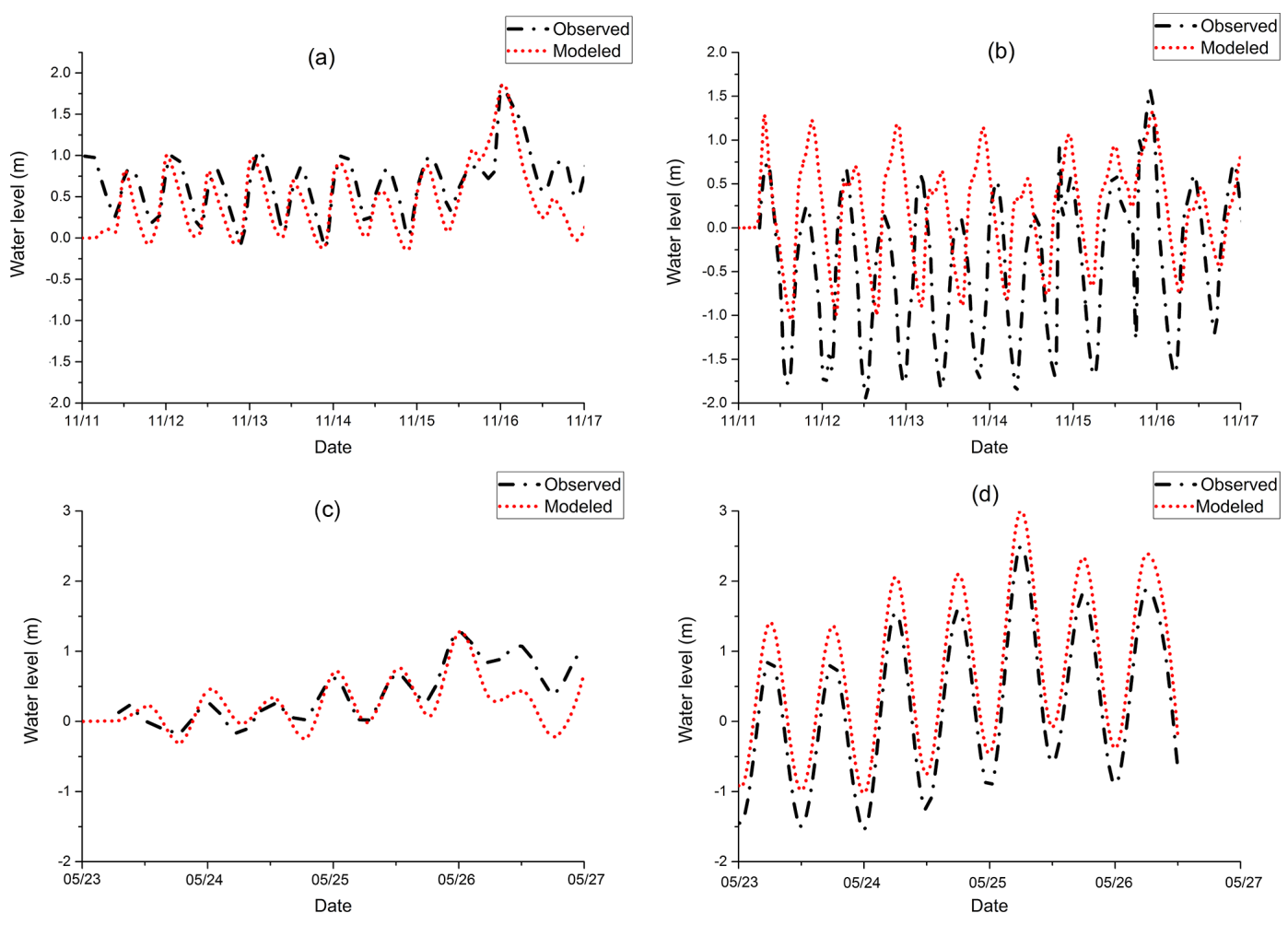

Figure 3. Comparison of observed and modelled water levels for TC Sidr and TC Aila at Barisal and Charchanga observation stations. (a) Measured and modelled water level comparison for TC Sidr in Barisal, (b) TC Sidr in Charchanga, (c) TC Aila in Barisal and (d) TC Aila in Charchanga.

\section{Results}

\subsection{Validation of the model}

Hourly tidal data from the Bangladesh Inland Water Transport Authority (BIWTA) were used to evaluate the performance of the model used in this study. The model simulation's root mean square error $(\mathrm{RMSE})^{7}$, mean absolute error $(\mathrm{MAE})^{8}$ and dimensionless Nash-Sutcliffe coefficient $(E)^{9}$ (Nash and Sutcliffe, 1970) were calculated and listed in Table 4. A Nash-Sutcliffe coefficient ranges between negative infinity (no skill simulation) and one (perfect simulation).

RMSE $=\sqrt{\frac{\sum_{i=1}^{n}\left(X_{\mathrm{obs}, i}-X_{\text {model }, i}\right)^{2}}{n}}$

$\mathrm{MAE}=\frac{1}{n} \sum_{i=1}^{n}\left|X_{\mathrm{obs}, i}-X_{\mathrm{model}, i}\right|$

$E=1-\frac{\sum_{i=1}^{n}\left(X_{\mathrm{obs}, i}-X_{\mathrm{model}}\right)^{2}}{\sum_{i=1}^{n}\left(X_{\mathrm{obs}, i}-\overline{X_{\mathrm{obs}}}\right)^{2}}$
The simulated water levels were compared against the measured data from BIWTA at two locations: Barisal and Charchanga (Fig. 1a). Barisal station is located more towards the inland, whereas Charchanga is located near the coastline, where the grid cell resolution was coarse. However, none of them are in the open ocean water, which is important for getting a clear idea about storm surge level. TC Sidr made landfall near Barisal station (Fig. 1a) and the impact of the storm surge was clearer at Barisal station than that of TC Aila, which made landfall outside the model domain (Fig. 1a); therefore, its impact was not as clear as that of Sidr.

In Fig. 3a for TC Sidr at Barisal station, the modelled water level, including storm surge and astronomical tides, was slightly lower than the observations, and at Charchanga station (Fig. 3b) the measured water level variation displayed smaller amplitudes than the model outputs for positive tides, larger amplitudes than the modelled water level for negative tides, perhaps due to the coarse resolution of bathymetry. Similar types of variation between measured and modelled water level were found for TC Aila (Fig. 3c and d). Nevertheless, the modelled water level variations during TCs Sidr and Aila agreed reasonably well with measured data, as also confirmed by the calculated RMSE, MAE and Nash-Sutcliffe coefficient (Table 4). Therefore, we conclude that the method 
Table 2. List of 12 historical TC events used for ensemble projection of storm surge inundation.

\begin{tabular}{lllr}
\hline Name & Date & $\begin{array}{l}\text { Landfall } \\
\text { location }\end{array}$ & $\begin{array}{r}\text { Maximum } \\
\text { sustained } \\
\text { wind } \mathrm{km} \mathrm{h}^{-1} \text { ) }\end{array}$ \\
\hline Tropical storm 13 & 14-18 November 1973 & Noakhali & 102 \\
Cyclone 12 & 23-28 November 1974 & Bhola & 139 \\
Tropical storm 19 & 7-12 November 1975 & Chittagong & 93 \\
Tropical storm 1 & 22-25 May 1985 & Noakhali & 110 \\
Cyclone 4 & 21-30 November 1988 & Khulna & 205 \\
Cyclone 2 & 22-30 April 1991 & Chittagong & 235 \\
Cyclone 2 & 26 April-2 May 1994 & Cox's Bazar & 215 \\
Cyclone 4 & 18-25 November 1995 & Cox's Bazar & 190 \\
Cyclone 1 & 13-20 May 1997 & Noakhali & 165 \\
Tropical storm 4 & 24-27 October 2008 & Barguna & 85 \\
Tropical storm Mahasen & 10-16 May 2013 & Patuakhali & 85 \\
Tropical storm Roanu & 18-21 May 2016 & Chittagong & 110 \\
\hline
\end{tabular}

Table 3. Parameters considered for ensemble projection of storm surge inundation, which includes the TC intensities, tidal conditions and the SLR scenarios.

\begin{tabular}{llll}
\hline TC name & Intensities & Tide conditions & SLR \\
\hline TC Sidr & $+10 \%$, present day, $-10 \%$ & high, low, actual, zero & present day, $0.26,0.54 \mathrm{~m}$ \\
TC Aila & $+10 \%$, present day, $-10 \%$ & high, low, actual, zero & present day, $0.26,0.54 \mathrm{~m}$ \\
12 historical TC tracks & actual intensities & actual & present day, $0.26,0.54 \mathrm{~m}$ \\
\hline
\end{tabular}

can be used to study the impact of SLR on storm surge and inundation in future climate change scenarios.

\subsection{Present-day inundation scenario}

The storm surge inundation scenarios due to the two TCs considered are shown in Fig. 4. It can be seen from Fig. 4 that the area flooded by TC Sidr (yellow and red shaded) was much larger than the area flooded by TC Aila (white and red shaded), a result that is consistent with the fact that the Category 5 TC Sidr was much stronger than the Category 1 TC Aila and directly hit the study area. The maximum sustained wind speed for TC Sidr was $260 \mathrm{~km} / \mathrm{h}$, whereas for TC Aila it was $110 \mathrm{~km} \mathrm{~h}^{-1}$. The landfall location of Sidr was on the eastern side of Sundarban, while for Aila, the landfall location was towards the western side of Sundarbans. That explains why the inundations due to TC Sidr were located near the eastern side of Sundarban, whereas for Aila, the inundation was located mainly in the western part. The extent of inundation due to $\operatorname{Sidr}\left(1860 \mathrm{~km}^{2}\right)$ was $54 \%$ larger than that of Aila $\left(1208 \mathrm{~km}^{2}\right)$.

Sakib et al. (2015) showed that Sundarban acted as a buffer zone in reducing the impact of Sidr and thereby reduced much of the potential inundation depth and extent of flooding. As mentioned before, in the model simulation the impact of Sundarban was realized using a higher Manning's roughness value as resistance against the surge.
Table 4. Computed values of RMSE, MAE and Nash-Sutcliffe coefficient for both TC Sidr and TC Aila.

\begin{tabular}{lccccccc}
\hline Stations & \multicolumn{3}{c}{ TC Sidr } & & \multicolumn{3}{c}{ TC Aila } \\
\cline { 2 - 4 } \cline { 7 - 9 } & $\begin{array}{c}\text { RMSE } \\
(\mathrm{m})\end{array}$ & $\begin{array}{c}\text { MAE } \\
(\mathrm{m})\end{array}$ & NASH & & $\begin{array}{c}\text { RMSE } \\
(\mathrm{m})\end{array}$ & $\begin{array}{c}\text { MAE } \\
(\mathrm{m})\end{array}$ & NASH \\
\hline Barisal & 0.23 & 0.16 & 0.85 & & 0.33 & 0.24 & 0.65 \\
Charchanga & 0.26 & 0.19 & 0.80 & & 0.28 & 0.17 & 0.73 \\
\hline
\end{tabular}

\subsection{Impact of future climate scenarios on storm surge inundation}

Future inundation scenarios were generated for two different time horizons: one for the mid-21st century and the other for the end-21st century. The initial ocean water level rose by $0.26 \mathrm{~m}$ and $0.54 \mathrm{~m}$ for the mid-21st century and end-21st century. The upstream river discharge and downstream ocean water level were used from present-day climate scenarios.

In this section we seek to answer the following question: if present-day TCs were to happen in future SLR scenarios, what storm surge and inundation hazard would they cause? Therefore, the tracks and intensities of the two present-day TCs, Sidr and Aila, were used as the model wind input parameters.

The model-simulated inundated areas and the percent variations were shown in Table 5 and Fig. 5. Figure 5 shows that under future SLR scenarios, the inundated areas caused 


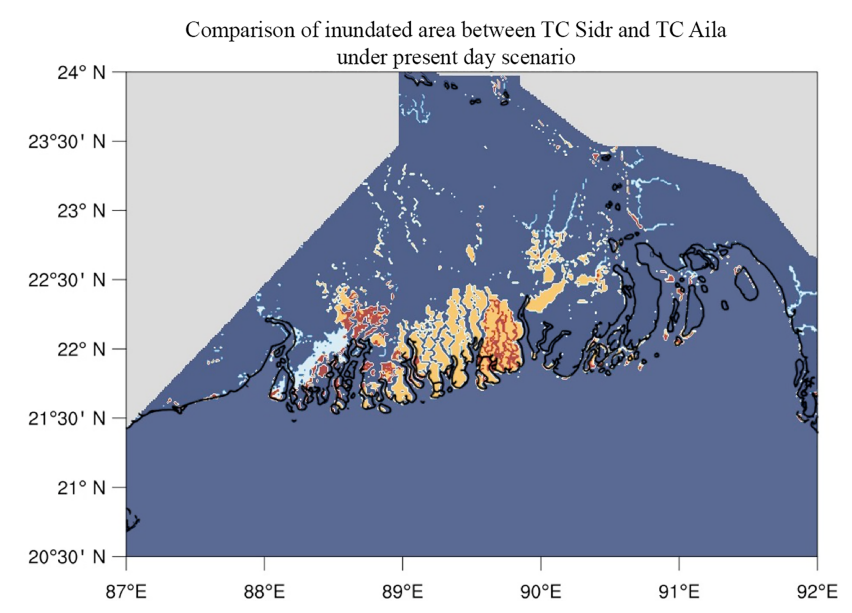

Figure 4. Yellow denotes the areas flooded by TC Sidr but not by Aila, and the white represents the area inundated by TC Aila but not by Sidr. Red is the area flooded by both TC Sidr and TC Aila. Blue shows the non-flooded area (either land or constant water).

by TCs Sidr and Aila would be significantly larger than those under the present-day climate condition, as indicated by the white-shaded areas. For the Category 5 TC Sidr, the inundated area would be $31 \%\left(2437 \mathrm{~km}^{2}\right)$ and $53 \%$ $\left(2846 \mathrm{~km}^{2}\right)$ larger than present day's $1860 \mathrm{~km}^{2}$ inundated area, in mid-21st-century ( $0.26 \mathrm{~m} \mathrm{SLR})$ and end-21st-century (0.54 m SLR) climate scenarios, respectively (Fig. 5a and b).

Similarly, for the Category 1 TC Aila, there would be an increase in inundated areas. The simulated inundated areas for TC Aila under the mid-21st-century and end21 st-century scenarios were $1550 \mathrm{~km}^{2}(28 \%)$ and $1770 \mathrm{~km}^{2}$ (47\%) (Fig. 5c and d), whereas for the present-day scenario it was found to be $1208 \mathrm{~km},{ }^{2}$.

However, in Fig. 5, there are several small areas of yellow indicating zones flooded under present conditions but not flooded during future SLR conditions. This is because Fig. 5 showed snapshots of the inundation conditions at one particular time. Some areas may experience alternating wetting and drying conditions, which may explain why some areas are flooded with present SLR and not with higher SLR: this is the case only at a particular time. The authors expect that those areas are flooded at other times.

All these simulations were carried out using the presentday tides, upstream river discharges and TC tracks and strengths, with only the initial seawater level raised to reflect the effect of the projected future SLR. Therefore, the results suggest that even if the future TCs strengths, tides, and river discharges remain the same as in the present-day climate condition, future SLR would significantly increase the inundated area by as high as $53 \%$.
Table 5. Comparison of the inundated area between present-day and future SLR scenarios and calculated change in percentage with respect to the present-day scenario.

\begin{tabular}{lcllcll}
\hline \multirow{2}{*}{ SLR scenario } & \multicolumn{2}{c}{ TC Sidr } & & \multicolumn{2}{c}{ TC Aila } \\
\cline { 2 - 3 } \cline { 5 - 6 } & $\begin{array}{c}\text { Inundated } \\
\text { area }\left(\mathrm{km}^{2}\right)\end{array}$ & $\begin{array}{l}\text { Increase } \\
(\%)\end{array}$ & & $\begin{array}{l}\text { Inundated } \\
\text { area }\left(\mathrm{km}^{2}\right)\end{array}$ & $\begin{array}{l}\text { Increase } \\
(\%)\end{array}$ \\
\hline Present day & 1860 & $\mathrm{n} / \mathrm{a}$ & & 1208 & $\mathrm{n} / \mathrm{a}$ \\
Mid-21st century & 2437 & $31 \%$ & & 1550 & $28 \%$ \\
End-21st century & 2846 & $53 \%$ & & 1770 & $47 \%$ \\
\hline
\end{tabular}

n/a means not applicable.

\section{Ensemble projection of future storm surge inundation under SLR conditions}

As discussed in Sect. 2.2, the future change in storm surge inundation can vary based on the intensity, landfall location and timing of future TCs. By considering all these uncertainty factors mentioned in Table 3, a column plot was created (Fig. 6) for present-day sea level and future SLR scenarios. Ensemble simulation outputs also showed an evident increase in the inundated area under the effect of SLR. For the present-day scenario (black column), out of 36 simulations, frequency of storm surge inundation incidents that would likely occur in the range of $1000-1250 \mathrm{~km}^{2}$ is 13 . Whereas for $0.26 \mathrm{~m}$ of SLR (red column), peak of the column shifted towards the right with a maximum frequency of inundation events occurring within the range of $2000-2250 \mathrm{~km}^{2}$ (10 times out of 36 simulation results). For $0.54 \mathrm{~m}$ of increase in sea level (blue column), the peak of the column shifted more towards the right and the maximum number of simulation outputs (11 out of 36 simulations) showed the range of inundation to be within $3500-3750 \mathrm{~km}^{2}$. These results show that even though the change in intensities of future TCs is indefinite and the landfall timing is uncertain, an increase in sea level is going to increase the area of inundation.

\subsection{Impact of sea level rise on future storm surge level}

In addition to the inundated area, SLR would also greatly affect storm surge levels. Similarly to the approach used in the inundation study (Sect. 3.3), TCs Sidr- and Aila-induced storm surges in the future SLR scenarios were simulated using their recorded strengths.

The simulated storm surge water levels in the future SLR scenarios were compared with both the observed and model generated ones under the present-day scenarios (Fig. 7). It is to be mentioned that, while generating the future water level under the effect of SLR, the baseline was only changed by considering the SLR effect and based on that factor the future storm surge level was calculated. Apart from that, the water level is the same as present-day TCs.

From Fig. 7a and Table 6 we can see that for the case of TC Sidr the simulated storm surge level would become 

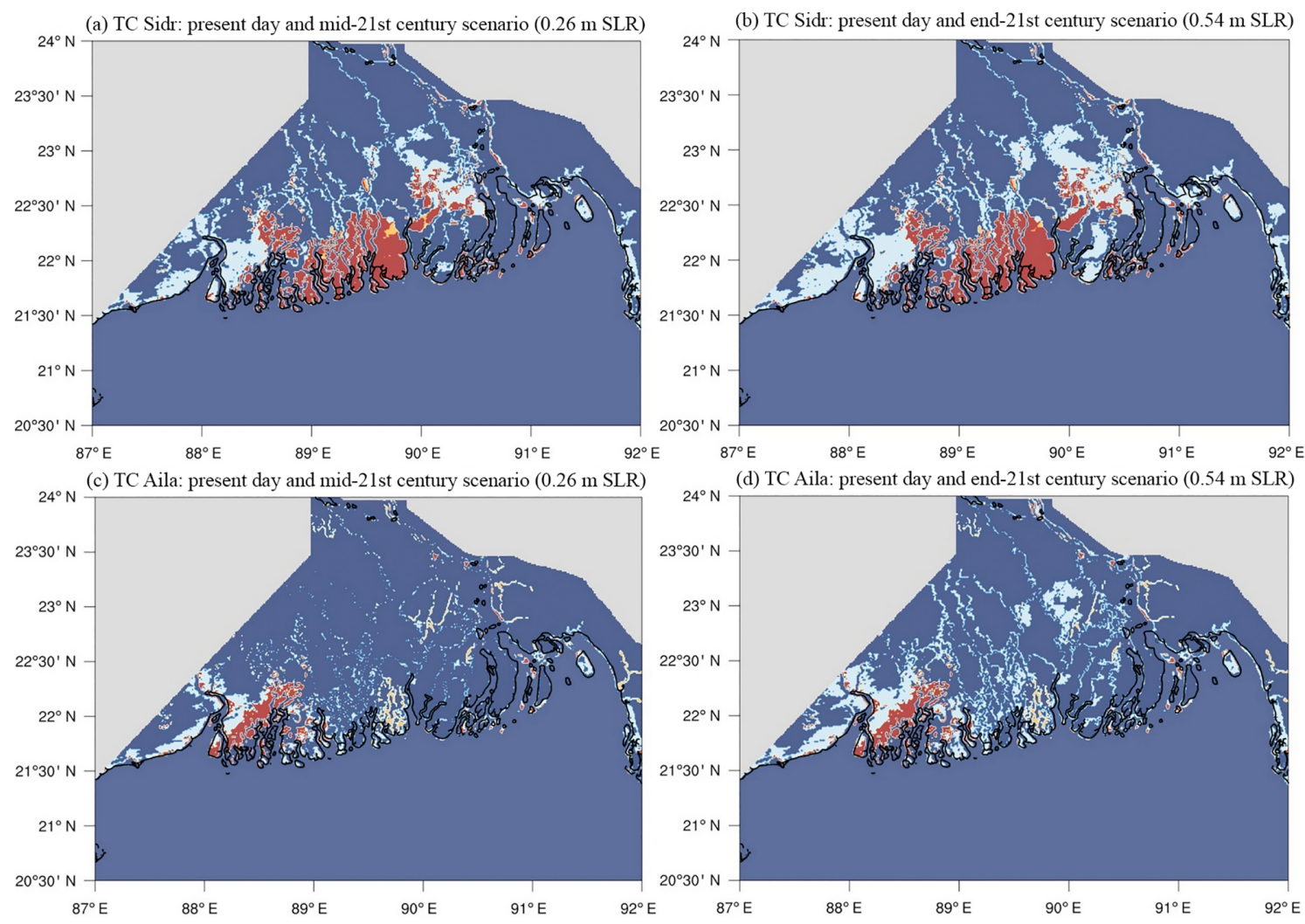

Figure 5. Comparison of the inundated areas between present-day and future climate scenarios for (a) TC Sidr mid-21st century $0.26 \mathrm{~m} \mathrm{SLR}$, (b) TC Sidr end-21st century $0.54 \mathrm{~m} \mathrm{SLR,} \mathrm{(c)} \mathrm{TC} \mathrm{Aila} \mathrm{mid-21st} \mathrm{century} 0.26 \mathrm{~m}$ SLR and (d) TC Aila end-21st century $0.54 \mathrm{~m}$ SLR. White represents the flooded areas that were not in the present-day scenario but were flooded due to future SLR. Red shows the inundated areas that were similar both for present-day and future SLR scenario.

$2.13 \mathrm{~m}$ at Barisal station, which is around $14 \%$ higher than the present-day scenario. Similarly to that, under the end21 st century $0.54 \mathrm{~m}$ SLR scenario in Barisal, the storm surge would be around $29 \%$ higher than the present-day scenario and the peak water level would reach $2.41 \mathrm{~m}$.

An increase in storm surge was also found at Charchanga station. For TC Sidr, under the mid-21st-century scenario $(0.26 \mathrm{~m} \mathrm{SLR})$, the model-simulated storm surge level was found to be $14 \%$ higher $(1.87 \mathrm{~m})$ than the present day and $34 \%$ higher $(2.19 \mathrm{~m})$ (Fig. $7 \mathrm{~b}$, Table 6$)$ than the present day for the end-21st-century ( $0.54 \mathrm{~m} \mathrm{SLR})$ climate scenario. It is to be noted that a slight phase shift in the model simulation occurred at this station from 13 to 15 November. This could happen due to the presence of a seiche. However, for rest of the period, phase variations are similar to the observed ones.

For TC Aila in Barisal, under the mid-21st-century SLR scenario the storm surge would become $22 \%$ higher $(1.58 \mathrm{~m})$ than the present day, which was $1.29 \mathrm{~m}$ (Fig. 7c, Table 6). During the end-21st-century climate scenario, the increment would become even higher as the SLR would be $0.54 \mathrm{~m}$. Storm surge under the $0.54 \mathrm{~m}$ end-21st-century SLR condition would be $52 \%$ higher $(1.96 \mathrm{~m})$ than the present day.
At Charchanga, the storm surge would be higher than the present-day condition for TC Aila. Under the $0.26 \mathrm{~m}$ mid21 st-century SLR scenario, the storm surge would become $3.07 \mathrm{~m}$ which is $23 \%$ higher than the present-day condition (Fig. 7d, Table 6). And for the end-21st century, this would be $55 \%$ higher $(3.87 \mathrm{~m})$ than the present day.

To analyse the linearity/non-linearity of storm surge level with respect to SLR, we conducted additional experiments based on 5 SLR scenarios; present-day sea level, $0.26 \mathrm{~m}$ of SLR, $0.33 \mathrm{~m}$ of SLR, $0.4 \mathrm{~m}$ of SLR, $0.47 \mathrm{~m}$ of SLR, $0.54 \mathrm{~m}$ of SLR, respectively. Results from these experiments are presented in Table 6.

For the case of TC Sidr at Barisal and Charchanga stations, storm surge level increased almost linearly with respect to the addition of water due to the effect of SLR. For example, with a SLR of $0.47 \mathrm{~m}$, the percentage increases in storm surge level with the SLR scenarios at Barisal and Charchanga stations were 96 and $94 \%$, respectively (Table 6). On the other hand, for the case of TC Aila, with a SLR of $0.26 \mathrm{~m}$, the increases in storm surge level were found to be 112 and $219 \%$ respectively for Barisal and Charchanga stations (Table 6). The increase in storm surge level for TC Aila at Charchanga station is significantly higher than what we found at Barisal 


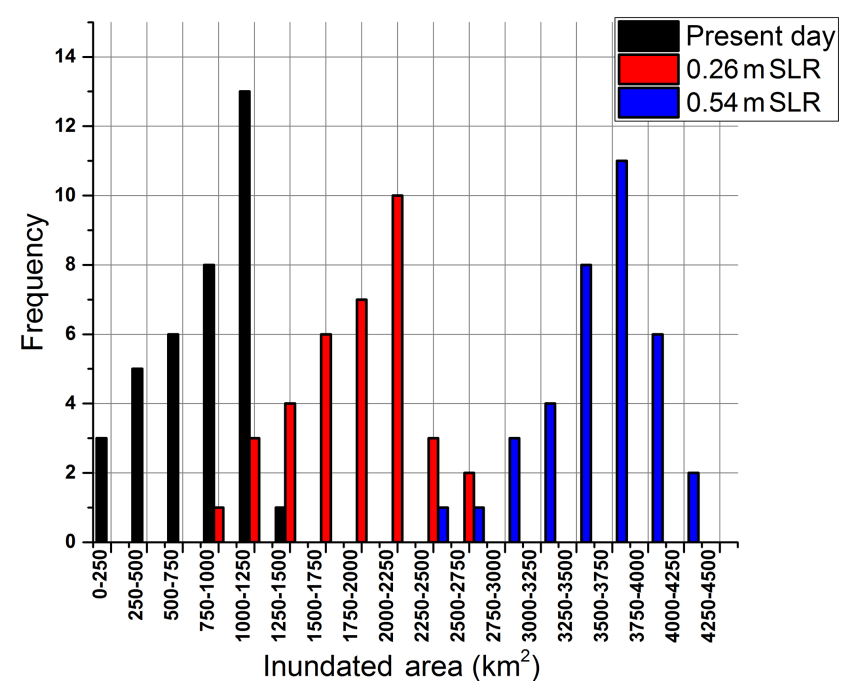

Figure 6. Ensemble projection of the future SLR impact on storm surge inundation. The column in black represents the inundation events for the present-day sea level condition, the red one is for $0.26 \mathrm{~m}$ of SLR and the blue column is for $0.54 \mathrm{~m}$ of SLR conditions. In total 108 simulations were conducted for one present and two future SLR scenarios.

station (Table 6). This difference is likely due to the different roles played by the topography and bathymetry near the two stations and their coarse resolution in the model grid. In the absence of strong interaction with the bottom topography, the increase in peak water level during the TCs should approximately match the mean SLR. However, both Charchanga and Barisal are located away from the open water, and thus the complex topography and bathymetry play a role in regulating water levels in a complex way. The large simulated storm surge level increase for TC Aila at Charchanga station may be unrealistic and in our opinion, it is an artificial effect due to the coarse resolution of the model grid near the station.

\section{Discussions}

In this paper, we showed that even if the future TCs keep the same strength as the present-day ones their impact will be much higher in a changing climate due to the effect of SLR. Several other factors not included in the modelling could make the storm surge and inundation situation far worse than that shown in the modelling result. These factors include mangrove coverage decrease, morphological changes, TC strength increase, and upstream river discharge changes.

For including the effect of future SLR in the model simulations, several methodologies were examined. One of the methods with which we experimented in this study was to include the increased sea level in open ocean boundary instead of adding it in to the whole ocean depth by keeping the coastline fixed. This method was used by some previous studies (Pickering et al., 2012). However, in such a case, an
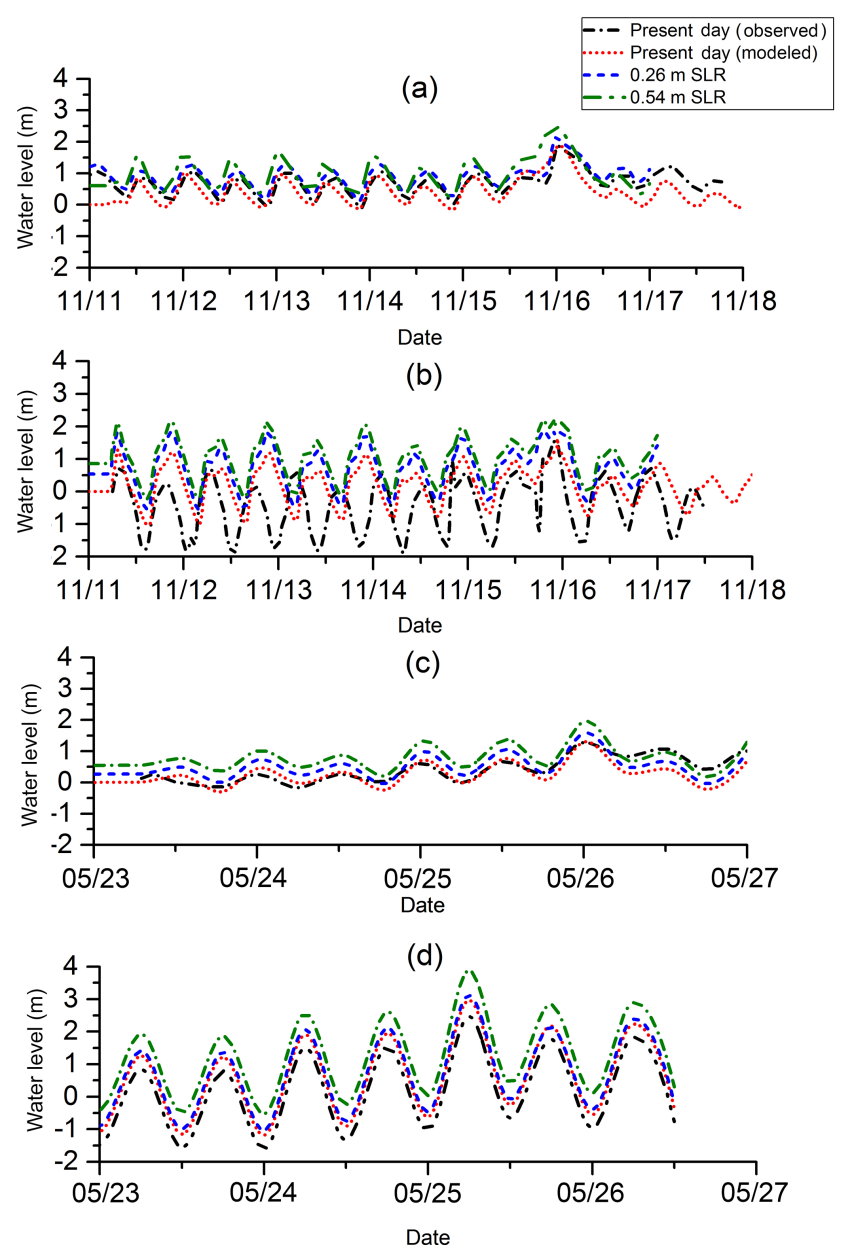

Figure 7. Comparison of storm surge water levels between presentday and future SLR scenarios. (a) TC Sidr at Barisal, (b) TC Sidr at Charchanga, (c) TC Aila at Barisal and (d) TC Aila at Charchanga. The observed, modelled present-day, mid-21st-century and end21 st-century storm surge levels are denoted by the black dasheddotted, red-dotted, blue-dashed and green dash-dotted lines.

additional pressure gradient force was found acting towards the coast which made the inundated area much larger. Therefore, this method was not used in this study. Instead, in this study, the future SLR was added to the whole ocean domain depth.

To make the future SLR simulation realistic, we considered the increased sea level in ocean bathymetry and increased the depths by 0.26 and $0.54 \mathrm{~m}$ by considering land submergence near the coast. In that case, the result looked much more realistic than the previous one and this is the method we followed in this paper. For example, for the case of TC Aila under the end-21st-century scenario in which we used a SLR of $0.54 \mathrm{~m}$ at the open ocean boundary instead of adding it to ocean depth and used the hydrodynamic conditions from the present day, the total inundated area was found to be $79 \%$ larger than the present-day one. Similarly to that, for the mid-21st-century scenario (a $0.26 \mathrm{~m} \mathrm{SLR}$ ), the inun- 
dated area was found to be $69 \%$ larger than the present-day scenario. However, when we added the SLR in ocean depth, the mid-21st-century and end-21st-century inundated areas were found to be 28 and $47 \%$ larger than the present-day scenario. This increase in the inundated area was much smaller than the one that we found by adding the SLR at the open ocean boundary. Figure 8 displays the differences in the inundated area based on the consideration of SLR in the model input.

As discussed earlier, TC Sidr made landfall near Sundarban, where the mangrove forest zone acted as a buffer in reducing the impact of the storm surge flood. That is why, even though it was a TC 5, its impact was not as high as might have been expected. In this study, the roughness of the mangrove forest zone on the south-western part of Bangladesh was considered to be fixed for the present day as well as for future scenarios. However, Mukhopadhyay et al. (2015) predicted that $17 \%$ of the total mangrove cover could disappear by 2105 . If this decreasing trend of vegetation was considered in this study, the flooded area could be much larger.

Morphological changes were not considered in this study, but according to Goodbred et al. (2003), each year the eastern, central and western estuaries lose land at rates of 0.13 , 0.16 and $0.16 \mathrm{~cm} \mathrm{yr}^{-1}$, respectively. This could also lead to increases in the inundated areas for future scenarios. As the focus of the paper is to estimate the future scenario of storm surge and inundation due to the effect of SLR and to compare them with the present-day scenarios, it is important that we keep the roughness and morphological changes constant so that consistent comparisons can be made.

Some previous research showed that there could be increases in hurricane strength and landfall probability in the future due to global climate change (Haarsma et al., 2013; Bender et al., 2010; Bengtsson et al., 2007). Though we slightly modified the present-day TC strengths and selected 12 historical TC tracks to reduce landfall uncertainties and to make an ensemble projection of future storm surge inundation, strength may be much higher than the ones that we considered for this study. In such case, the devastation could well be much greater under projected SLR conditions, which is very alarming

In this paper, we used the present-day river discharge data as an upstream boundary for generating future inundation scenarios. However, using the INCA-N, an inland catchment modelling system and considering the projected climatic and socioeconomic scenarios, Whitehead et al. (2015) showed that there would be a significant increase in future monsoon intensities due to the impact of climate change. That would make future flooding scenarios much worse than those experienced presently. So, based on the changes in TC intensity, river discharges, and land-use changes, the situation could well become more impacted than in this study.

The findings of our study are important for local governments to consider while they make new management and policy decisions and to improve TC preparedness plans by

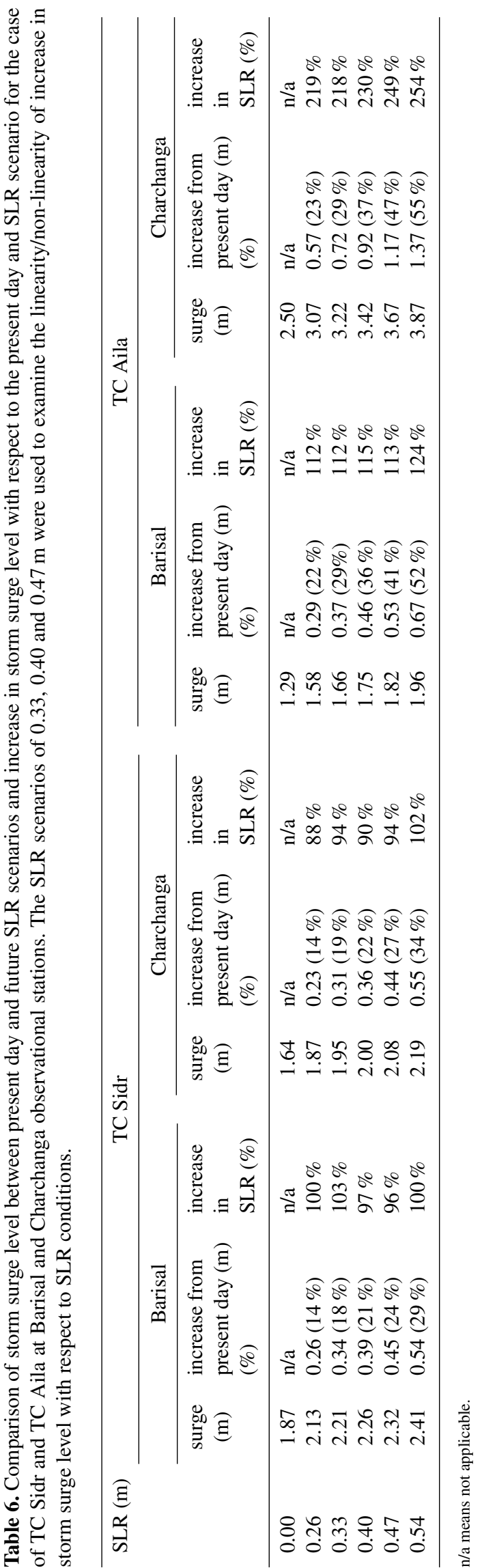

Nat. Hazards Earth Syst. Sci., 18, 351-364, 2018 
(a)

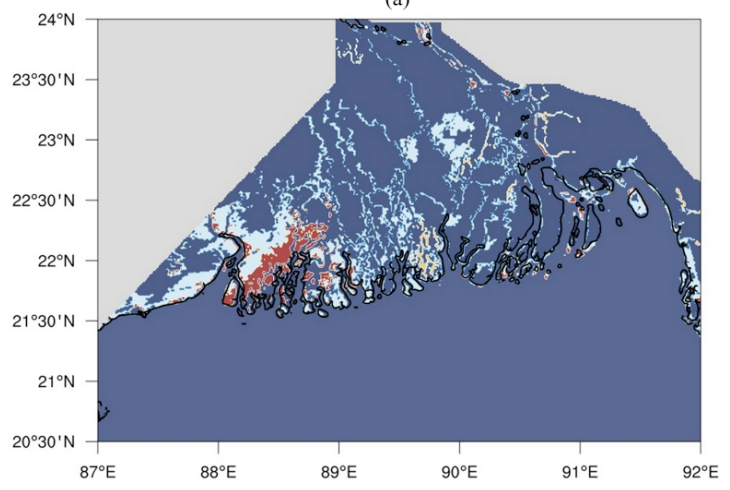

(b)

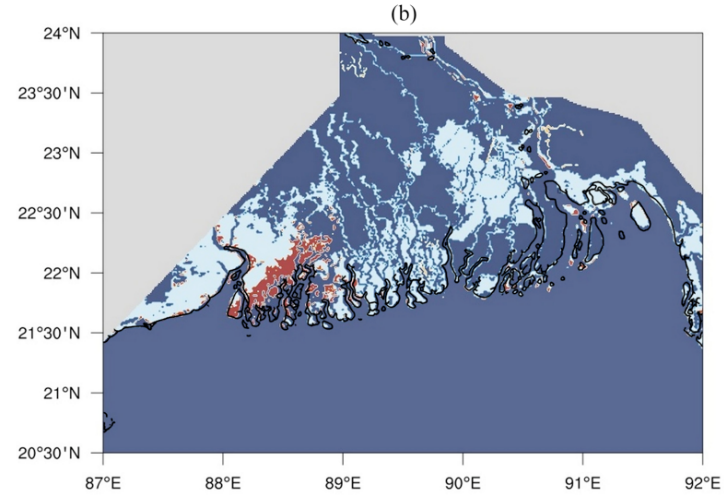

Figure 8. Comparison of inundated areas for TC Aila between the present day and end-21st-century (0.54 m SLR) scenario. White represents the flooded areas that were not in the present-day scenario but were flooded due to future SLR. Red shows the inundated area that is similar both for present-day and future scenario case. Blue areas are either land or constant waters (those which are already water at the model initialization time). Panel (a) represents the inundated area when SLR was considered on ocean depths instead of adding it to the open ocean boundary and (b) shows the inundated area when we considered the SLR on the ocean boundary.

increasing numbers of shelters and heights. In TC shelters, the first floor should be kept above the high surge waters. Our study showed that, in the future, there would be an increase in surge level from a minimum of $14 \%$ up to $55 \%$ if a TC 1 or a TC 5 makes landfall under increased SLR conditions (Table 6). So, the authority may consider increasing the height of the first floor due to the future risk of an increase in storm surge level and safety of local populations. Also, our model outputs showed that the inundated area increase would range from 28 to $53 \%$ (Table 5) if any TC 1 or TC 5 was to make landfall with SLRs of 0.26 or $0.54 \mathrm{~m}$. This shows that a huge number of new areas are going to face the impacts of storm surge inundation, and by considering this issue, it is high time to increase the number of TC shelters in the coastal areas of Bangladesh.

\section{Conclusion}

Employing the Delft3D-FLOW model, we simulated coastal storm surge and inundation for present-day and future SLR scenarios and compared the changes between them. After validating the present-day model, simulations were conducted for mid-21st century and end-21st century climate scenarios in which the SLRs have been found at $0.26 \mathrm{~m}$ and $0.54 \mathrm{~m}$ respectively. The model results showed that, with increases of $0.26 \mathrm{~m}$ and $0.54 \mathrm{~m}$ SLR, there would be increases of $31 \%$ and $53 \%$ in inundated area if TC Sidr was to make landfall with its present-day strength. There would also be increases of $28 \%$ and $47 \%$ in inundated area if Category 1 TC Aila was to make landfall with its present-day strength but under SLRs of $0.26 \mathrm{~m}$ and $0.54 \mathrm{~m}$. Outputs from the ensemble projections showed that, even if the TC intensities, landfall location and timings are uncertain, the most probable extent of the inundated area would shift from $1000-1250 \mathrm{~km}^{2}$ (present day) to $2000-2250 \mathrm{~km}^{2}$ (under $0.26 \mathrm{~m}$ SLR sce- nario) and $3500-3750 \mathrm{~km}^{2}$ (under $0.54 \mathrm{~m}$ SLR scenario). Besides the inundated area, we investigated the changes in storm surge level if TC Sidr and TC Aila were to make landfall under future SLR conditions. Similarly to the inundated area, increases in storm surge levels were found for future scenarios. The significant increase in simulated storm surge and inundation hazards highlights the need for local governments to improve cyclone preparedness in future SLR scenarios.

Data availability. Tropical cyclone tracking data used in this study were collected from the Indian Meteorological Department's Regional Specialized Meteorological Centre's Best Track archive (http://www.rsmenewdelhi.imd.gov.in/). The ocean bathymetry data are available from https://www.gebco.net/. The model outputs are available upon request from the authors.

Competing interests. The authors declare that they have no conflict of interest.

Acknowledgements. The authors would like to thank Coastal Carolina University's Cyberinfrastructure Project (http://ci.coastal.edu) for providing access to computational resources. Also, we would like to acknowledge Susan Kay from Plymouth Marine Laboratory, UK for her thoughtful opinions regarding the SLR input in model and Institute of Water and Flood Management, Bangladesh for providing important data and support for this work. The authors also appreciate the helpful comments and suggestions from the three anonymous reviewers. The computation was conducted on the Coastal Carolina University Cyberinfrastructure Project and the National Science Foundation's Extreme Science and Engineering Discovery Environment (XSEDE) project. 
Edited by: Piero Lionello

Reviewed by: three anonymous referees

\section{References}

Ali, A.: Vulnerability of Bangladesh to climate change and sea level rise through tropical cyclones and storm surges, in: Climate Change Vulnerability and Adaptation in Asia and the Pacific, Springer, the Netherlands, 171-179, https://doi.org/10.1007/97894-017-1053-4_16, 1996.

Bender, M. A., Knutson, T. R., Tuleya, R. E., Sirutis, J. J., Vecchi, G. A., Garner, S. T., and Held, I. M.: Modeled impact of anthropogenic warming on the frequency of intense Atlantic hurricanes, Science, 327, 454-458, https://doi.org/10.1126/science.1180568, 2010.

Bengtsson, L., Hodges, K. I., Esch, M., Keenlyside, N., Kornblueh, L., Luo, J.-J., and Yamagata, T.: How may tropical cyclones change in a warmer climate?, Tellus A, 59, 539-561, https://doi.org/10.1111/j.1600-0870.2007.00251.x, 2007.

BODC.: Centenary Edition of the GEBCO Digital Atlas, published on CD-ROM on behalf of the Intergovernmental Oceanographic Commission and the International Hydrographic Organization as part of the General Bathymetric Chart of the Oceans, British oceanographic data centre, Liverpool, 2003.

Caesar, J., Janes, T., and Lindsay, A.: Climate projections over Bangladesh and the upstream Ganges-Brahmaputra-Meghna system, under review, Environ. Sci. Process. Imp., in review, 2017.

Delft Hydraulics: Delft3D-FLOW user manual, Delft, the Netherlands, 2006.

Delft Hydraulics: Wind Enhancement Scheme for cyclone modelling, Delft, the Netherlands, 2011.

Egbert, G. D., Bennett, A. F., and Foreman, M. G. G.: TOPEX/POSEIDON tides estimated using a global inverse model, J. Geophys. Res., 99, 24821-24852, https://doi.org/10.1029/94JC01894, 1994.

Goodbred, S. L., Kuehl, S. A., Steckler, M. S., and Sarker, M. H.: Controls on facies distribution and stratigraphic preservation in the Ganges-Brahmaputra delta sequence, Sediment. Geol., 155, 301-316, https://doi.org/10.1016/S0037-0738(02)00184-7, 2003.

Haarsma, R. J., Hazeleger, W., Severijns, C., Vries, H., Sterl, A., Bintanja, R., Oldenborgh, G. J., and Brink, H. W.: More hurricanes to hit western Europe due to global warming, Geophys. Res. Lett., 40, 1783-1788, https://doi.org/10.1002/grl.50360, 2013.

Haque, C. E.: Atmospheric hazards preparedness in Bangladesh: a study of warning, adjustments and recovery from the April 1991 cyclone, in: Earthquake and Atmospheric Hazards, Springer, the Netherlands, 181-202, https://doi.org/10.1007/978-94-0115034-7_6, 1997.

Harris, D. L.: Characteristics of the hurricane storm surge, Tech. Pap. 48, US Weather Bureau, Washington, D. C., 139 pp., 1963.

Hearn, C. J.: The dynamics of coastal models, Cambridge University Press, Cambridge, 2008.

Heming, J. T., Chan, J. C. L., and Radford, A. M.: A new scheme for the initialization of tropical cyclones in the UK
Meteorological Office global model, Met. Apps., 2, 171-184, https://doi.org/10.1002/met.5060020211, 1995.

Holland, G. J.: An analytic model of the wind and pressure profiles in hurricanes, Mon. Weather Rev., 108, 1212-1218, https://doi.org/10.1175/15200493(1980)108<1212:AAMOTW>2.0.CO;2, 1980.

Karim, M. F. and Mimura, N.: Impacts of climate change and sea-level rise on cyclonic storm surge floods in Bangladesh, Global Environ. Change, 18, 490-500, https://doi.org/10.1016/j.gloenvcha.2008.05.002, 2008.

Knutson, T. R., McBride, J. L., Chan, J., Emanuel, K., Holland, G., Landsea, C., Held, I., Kossin, J. P., Srivastava, A. K., and Sugi, M.: Tropical cyclones and climate change, Nat. Geosci., 3, 157163, https://doi.org/10.1038/ngeo779, 2010.

Meehl, G. A., Stocker, T. F., Collins, W. D., Friedlingstein, A. T., Gaye, A. T., Gregory, J. M., Kitoh, A., Knutti, R., Murphy, J. M., Noda, A., Raper, S. C. B., Watterson, I. G., Weaver, A. J., and Zhao, Z.: Global climate projections, in: Climate Change 2007: The Physical Science Basis, edited by: Solomon, S., Qin, D., Manning, M., Marquis, M., Averyt, K., Tignor, M. M. B., Miller, H. J., and Chen, Z., Cambridge University Press, Cambridge, 2007.

Milliman, J. D., Broadus, J. M., and Gable, F.: Environmental and economic implications of rising sea level and subsiding deltas: the Nile and Bengal examples, Ambio, 18, 340-345, 1989.

Mukhopadhyay, A., Mondal, P., Barik, J., Chowdhury, S. M., Ghosh, T., and Hazra, S.: Changes in mangrove species assemblages and future prediction of the Bangladesh Sundarbans using Markov chain model and cellular automata, Environ. Sci. Process. Imp., 17, 1111-1117, https://doi.org/10.1039/C4EM00611A, 2015.

Murty, T. S., Flather, R. A., and Henry, R. F.: The storm surge problem in the Bay of Bengal, Prog. Oceanogr., 16, 195-233, https://doi.org/10.1016/0079-6611(86)90039-X, 1986.

Nash, J. E. and Sutcliffe, J. V.: River flow forecasting through conceptual models part I - A discussion of principles, J. Hydrol., 10, 282-290, https://doi.org/10.1016/0022-1694(70)90255-6, 1970.

Pickering, M. D., Wells, N. C., Horsburgh, K. J., and Green, J. A. M.: The impact of future sea-level rise on the European Shelf tides, Cont. Shelf Res., 35, 1-15, https://doi.org/10.1016/j.csr.2011.11.011, 2012.

Pietrafesa, L. J., Janowitz, G. S., Chao, T. Y., Weisberg, R. H., Askari, F., and Noble, E.: The physical oceanography of Pamlico Sound, University of North Carolina Sea Grant Publication UNC-WP-86-5, Raleigh, North Carolina, 125 pp., 1986.

Pietrafesa, L. J., Bao, S., Yan, T., Slattery, M., and Gayes, P. T.: On Sea Level Variability and Trends in United States Coastal Waters and Relationships with Climate Factors, Adv. Adapt. Data Anal., 7, 1550005, https://doi.org/10.1142/S1793536915500053, 2015.

Sakib, M., Nihal, F., Haque, A., Rahman, M., and Ali, M.: Sundarban as a Buffer against Storm Surge Flooding, World J. Eng. Technol., 3, 59-64, https://doi.org/10.4236/wjet.2015.33C009, 2015.

SMRC: The Vulnerability Assessment of the SAARC Coastal Region due to Sea Level Rise: Bangladesh Case, Dhaka SMRC-No. 3, SAARC Meteorological Research Center, Dhaka, Bangladesh, 2003. 
Vatvani, D. K., Gerritsen, H., Stelling, G. S., and Rao, A. K.: Cyclone induced storm surge and flood forecasting system for India, in: Solutions to Coastal Disasters '02, San Diego, CA, 2002.

Warrick, R. A., Bhuiya, A. A. H., Mitchell, W. M., Murty, T. S., and Rasheed, K. B. S.: Sea-level Changes in the Bay of Bengal, in: The Implications of Climate and Sea-Level Change for Bangladesh, Springer, the Netherlands, 97-142, 1996.

Whitehead, P. G., Barbour, E., Futter, M. N., Sarkar, S., Rodda, H., Caesar, J., Butterfield, D., Jin, L., Sinha, R., Nicholls, R., and Salehin, M.: Impacts of climate change and socioeconomic scenarios on flow and water quality of the Ganges, Brahmaputra and Meghna (GBM) river systems: low flow and flood statistics, Environ. Sci. Process. Imp., 17, 1057-1069, https://doi.org/10.1039/C4EM00619D, 2015.
Xie, L., Bao, S., Pietrafesa, L. J., Foley, K., and Fuentes, M.: A real-time hurricane surface wind forecasting model: Formulation and verification, Mon. Weather Rev., 134, 1355-1370, https://doi.org/10.1175/MWR3126.1, 2006.

Zhang, K., Liu, H., Li, Y., Xu, H., Shen, J., Rhome, J., and Smith, T. J.: The role of mangroves in attenuating storm surges, Estuarine, Coast. Shelf Sci., 102, 11-23, https://doi.org/10.1016/j.ecss.2012.02.021, 2012. 